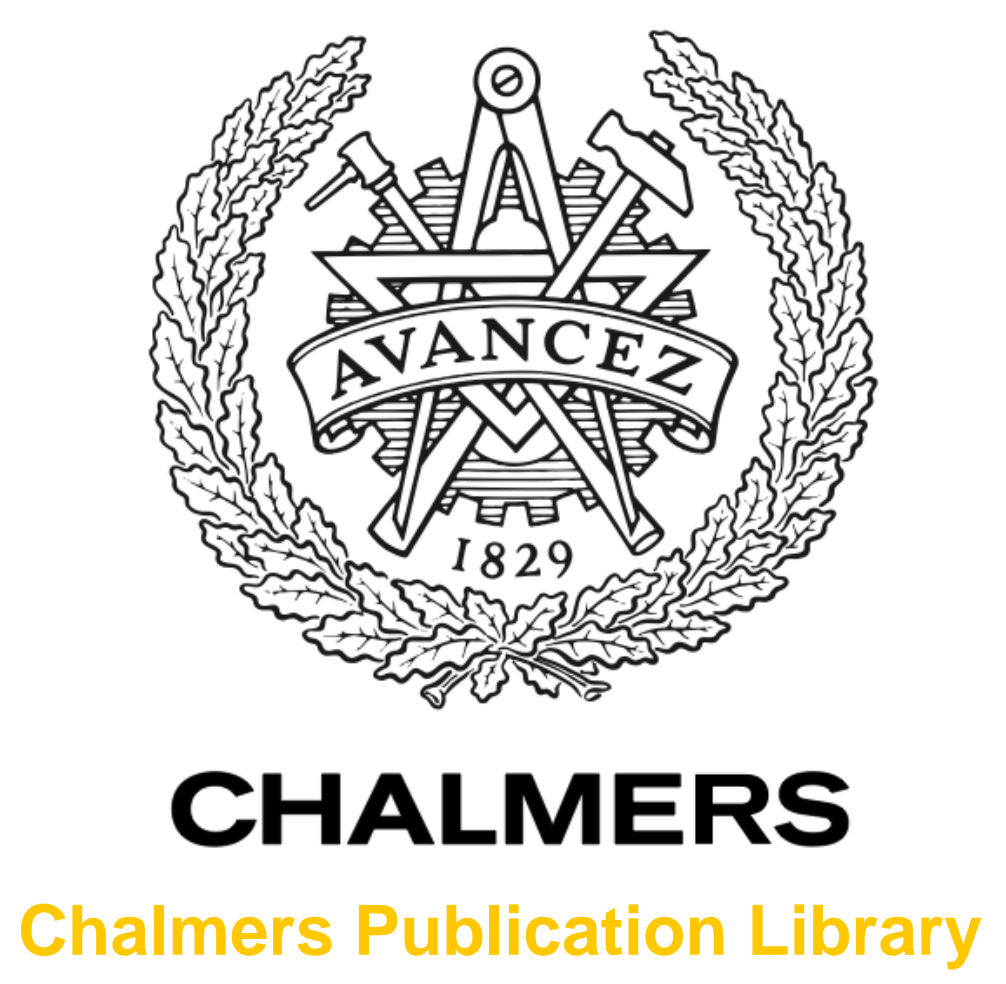

\title{
Development and testing of bioelectrochemical reactors converting wastewater organics into hydrogen peroxide
}

This document has been downloaded from Chalmers Publication Library (CPL). It is the author's version of a work that was accepted for publication in:

Water Science and Technology (ISSN: 0273-1223)

Citation for the published paper:

Modin, O. ; Fukushi, K. (2012) "Development and testing of bioelectrochemical reactors converting wastewater organics into hydrogen peroxide". Water Science and Technology, vol. 66(4), pp. 831-836.

http://dx.doi.org/10.2166/wst.2012.255

Downloaded from: http://publications.lib.chalmers.se/publication/163009

Notice: Changes introduced as a result of publishing processes such as copy-editing and formatting may not be reflected in this document. For a definitive version of this work, please refer to the published source. Please note that access to the published version might require a subscription. 


\title{
Development and testing of bioelectrochemical reactors converting wastewater organics into hydrogen peroxide
}

\author{
Oskar Modin****, Kensuke Fukushi**
}

\author{
*Divison of Water Environment Technology, Department of Civil \& Environmental Engineering, \\ Chalmers University of Technology, SE-41296, Gothenburg, Sweden \\ (E-mail: oskar.modin@chalmers.se) \\ **Integrated Research System for Sustainability Science (IR3S), The University of Tokyo, 7-3-1 \\ Hongo, Tokyo 113-8654, Japan \\ (E-mail: fukushi@ir3s.u-tokyo.ac.jp)
}

\begin{abstract}
In a bioelectrochemical system, the energy content in dissolved organic matter can be used to power the production of hydrogen peroxide $\left(\mathrm{H}_{2} \mathrm{O}_{2}\right)$, which is a potentially useful chemical at wastewater treatment plants. $\mathrm{H}_{2} \mathrm{O}_{2}$ can be produced by the cathodic reduction of oxygen. We investigated four types of gas-diffusion electrodes (GDEs) for this purpose. A GDE made of carbon nanoparticles bound with $30 \%$ polytetrafluoroethylene (PTFE) (wt./wt.C) to a carbon fiber paper performed best and catalyzed $\mathrm{H}_{2} \mathrm{O}_{2}$ production from oxygen in air with a coulombic efficiency of $95.1 \%$. We coupled the GDE to biological anodes in two bioelectrochemical reactors. When the anodes were fed with synthetic wastewater containing acetate they generated a current of up to $\sim 0.4 \mathrm{~mA} / \mathrm{mL}$ total anode compartment volume. $\mathrm{H}_{2} \mathrm{O}_{2}$ concentrations of $\sim 0.2 \%$ and $\sim 0.5 \%$ could be produced in 5 $\mathrm{mL}$ catholyte in $9 \mathrm{hrs}$ and $21 \mathrm{hrs}$, respectively. When the anodes were fed with real wastewater, the generated current was $\sim 0.1 \mathrm{~mA} / \mathrm{mL}$ and only $84 \mathrm{mg} / \mathrm{L}$ of $\mathrm{H}_{2} \mathrm{O}_{2}$ was produced.
\end{abstract}

Keywords: Bioelectrochemical systems; hydrogen peroxide; wastewater treatment; microbial fuel cell

\section{INTRODUCTION}

In bioelectrochemical systems (BESs), organics are oxidized by bacteria and the electrons are shuttled into an electrode called the anode. The electrons flow as a current through an external circuit to another electrode, the cathode, where a compound is reduced (Rozendal et al., 2008). The most commonly investigated type of BES is the microbial fuel cell (MFC), which is used to recover electrical energy from organic compounds in e.g. wastewater. In a MFC, oxygen is typically reduced to water at the cathode. Electrical energy can be recovered because the overall reaction, i.e. oxidation of organic compounds at the anode and oxygen reduction at the cathode is thermodynamically favorable (Logan et al., 2006). Another type of BES is the microbial electrolysis cell (MEC) for hydrogen production. Protons are reduced to hydrogen gas at the cathode. This occurs at a redox potential that is lower than the oxidation of organics at the anode, which means that the overall reaction is thermodynamically unfavorable. Thus, a small voltage input is needed to drive the reactions. However, because of the oxidation of organics at the anode, the energy value of the produced hydrogen can be significantly higher than the required input of electrical energy (Liu et al., 2005; Rozendal et al., 2006). In addition to producing electrical energy and hydrogen, BESs could potentially be used for a variety of other purposes. Examples include methane production 
(Cheng et al., 2009), denitrification (Clauwaert et al., 2007), caustic production (Rabaey et al., 2010) or redistribution of alkalinity (Modin et al., 2011), ethanol production (Steinbusch et al., 2010), and perchlorate reduction (Trash et al., 2007).

We have focused on using a BES for production of hydrogen peroxide $\left(\mathrm{H}_{2} \mathrm{O}_{2}\right)$, which is a chemical that is useful in many applications. In a wastewater treatment plant, $\mathrm{H}_{2} \mathrm{O}_{2}$ could be used for effluent disinfection, advanced oxidation of recalcitrant organics, and cleaning of membranes in membrane bioreactor plants. Currently, most of the world's $\mathrm{H}_{2} \mathrm{O}_{2}$ is produced by the reduction of oxygen using the anthraquinone oxidation process, which requires use of hydrogen and non-aqueous solvents (Pletcher, 1999). However, $\mathrm{H}_{2} \mathrm{O}_{2}$ can also be produced electrochemically by the cathodic reduction of oxygen. Rozendal et al. (2009) showed that a BES can be used to produce $\mathrm{H}_{2} \mathrm{O}_{2}$ with a low energy cost. They produced a concentration of $0.13 \%$ with a voltage input of $0.5 \mathrm{~V}$ (Rozendal et al., 2009). Fu et al. (2010) produced $\mathrm{H}_{2} \mathrm{O}_{2}$ in a MFC, but could only generate a concentration of around $80 \mathrm{mg} / \mathrm{L}$ (Fu et al., 2010). MFCs have also been investigated for generation of Fenton's reagent at the cathode (Zhuang et al., 2010; Feng et al., 2010).

In this study we developed and tested bioelectrochemical reactors for conversion of organic matter into $\mathrm{H}_{2} \mathrm{O}_{2}$. We assumed a concentration of 0.2 to $0.5 \%$ would be sufficient to apply $\mathrm{H}_{2} \mathrm{O}_{2}$ as a cleaning agent in a membrane bioreactor treatment plant (Grelot et al., 2008); thus, producing a concentration in this range was our target. First, a gas-diffusion cathode was developed that allowed the production of sufficiently high concentrations of $\mathrm{H}_{2} \mathrm{O}_{2}$. Gas-diffusion electrodes (GDEs) are energy-efficient as they allow passive diffusion of oxygen from the air instead of air-sparging of the liquid. Second, the cathode was combined with a biological anode fed with synthetic wastewater containing acetate. The operational conditions of the biological anode were optimized to allow high current production. Third, the reactors were tested with real wastewater.

\section{METHODS}

\section{Development of a gas-diffusion cathode}

The GDEs were constructed by painting a catalyst onto a hydrophobic carbon fiber paper (Toray TGP-H-090). Four conditions were tested: (1) the carbon fiber paper without any catalyst, (2) the paper coated with carbon black (Cabot Black Pearls 2000) and 480\% PTFE (wt. PTFE/wt. C), (3) the paper coated with 200 mesh graphite powder (Alfa Aesar) and 480\% PTFE, and (4) the paper coated with carbon black and 30\% PTFE. The GDEs were prepared by painting a slurry containing carbon and PTFE onto the carbon fiber paper, allowing the paper to air dry and then sintering it for about $20 \mathrm{~min}$ at $350^{\circ} \mathrm{C}$. PTFE is used as a binder that glues the catalysts layer to the carbon fiber paper. The performance of the GDEs was tested in an electrochemical cell consisting of $2.7 \mathrm{ml}$ anode and cathode compartments separated by a Nafion 117 proton exchange membrane. The cathode surface area was $1.3 \mathrm{~cm}^{2}$ and $50 \mathrm{ml}$ of $50 \mathrm{mM} \mathrm{NaCl}$ was circulated through the cathode compartment using a peristaltic pump. The best performing GDE was then again tested in a slightly larger reactor having a $3.1 \mathrm{~cm}^{2}$ cathode surface area and $12 \mathrm{ml}$ cathode volume.

\section{Bioelectrochemical reactor}

Two cylindrical (diameter $=2 \mathrm{~cm}$ ) bioelectrochemical reactors were constructed. The reactors contained GDEs and Nafion membranes with surface areas of $3.14 \mathrm{~cm}^{2}$. The width of the anode compartments were $3 \mathrm{~cm}$ resulting in total volumes of approximately $9.4 \mathrm{ml}$. A graphite rod (diameter $=0.615 \mathrm{~cm}$, length $=3 \mathrm{~cm}$, Alfa Aesar) alone or together with a carbon fiber felt $(4 \times 3 \times 0.5 \mathrm{~cm}$, TMIL) was used as anode. In Reactor A, the width of the cathode compartment was $3 \mathrm{~cm}$ whereas in Reactor B, it was $1 \mathrm{~cm}$. The anode was fed with either a nutrient solution containing acetate 
(Modin et al., 2010) or real wastewater that had passed the preliminary treatment steps in a wastewater treatment plant in Tokyo. The catholyte was always $50 \mathrm{mM} \mathrm{NaCl}$.

\section{Analytical methods}

Cyclic voltammetry was performed using a potentiostat (KP07, Bank IC) and a data acquisition device (USB-6211, National Instruments) controlled with LabView software. The cathode was scanned at $10 \mathrm{mV} / \mathrm{s}$ whereas the anode was scanned at $1 \mathrm{mV} / \mathrm{s}$. The anode and cathode potentials were measured and controlled against $\mathrm{Ag} / \mathrm{AgCl}$ reference electrodes (BAS Inc.) but are reported against the Normal Hydrogen Electrode (NHE) assuming an offset of $0.197 \mathrm{~V} . \mathrm{H}_{2} \mathrm{O}_{2}$ concentration was measured spectrophotometrically using the titanium oxalate method (Sellers, 1980). Acetate concentrations were measured using ion chromatography (Metrohm 761 Compact IC). Coulombic efficiency of cathodic $\mathrm{H}_{2} \mathrm{O}_{2}$ production was calculated using Equation 1.

$C E=100 \% \times \frac{\Delta\left[H_{2} O_{2}\right] \times V \times(2 / 34)}{I \times(\Delta t / F)}$

where $C E$ is the coulombic efficiency $(\%), \Delta\left[\mathrm{H}_{2} \mathrm{O}_{2}\right]$ is the change in concentration over time $t$ (mg/L), $V$ is the catholyte volume (L), 2/34 converts $\mathrm{mg} \mathrm{H}_{2} \mathrm{O}_{2}$ into mmol e' required to reduce $\mathrm{O}_{2}$ to $\mathrm{H}_{2} \mathrm{O}_{2}, I$ is the current (mC/s), $\Delta t$ is length of time interval (s), $F$ is Faraday's constant $(96485.3$ $\left.\mathrm{mC} / \mathrm{mmol} \mathrm{e}^{-}\right)$.

\section{RESULTS AND DISCUSSION}

\section{Development of a gas-diffusion electrode}

A comparison of the four tested GDEs is shown in Figure 1. The GDEs coated with carbon nanoparticles (\#2 and \#4) supplied higher currents than the GDE without catalyst or coated with graphite powder, probably because of a significantly larger surface area. GDE 4, i.e. carbon fiber paper coated with carbon black and 30\% PTFE, performed the best (Fig. 1A). It supplied the largest cathodic current and it produced $\mathrm{H}_{2} \mathrm{O}_{2}$ with $95.1 \%$ efficiency when operated for 253 min at a constant cathode potential of $-0.31 \mathrm{~V}$ vs NHE (Fig. 1B). GDE 4 probably generated a higher current than GDE 2 because of the lower content of PTFE (30\% compared to 480\%). PTFE is hydrophobic; thus, a lower PTFE fraction led to a larger portion of the carbon nanoparticle layer being exposed to water, increasing the total surface area available for reaction.

\section{A}

Cathode $\mathrm{E}(\mathrm{V}$ vs NHE)
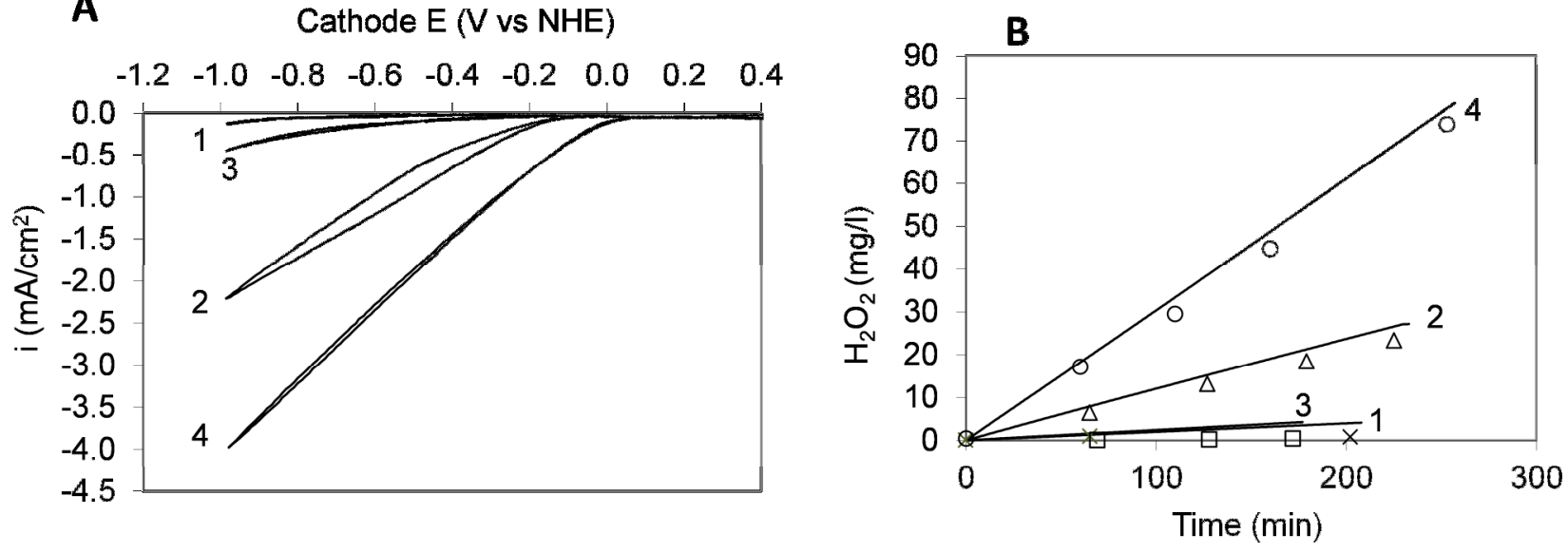

Figure 1. (A) Cyclic voltammograms of the four GDEs tested (cathodic current is negative). (B) Theoretical (line) and measured (symbols) $\mathrm{H}_{2} \mathrm{O}_{2}$ concentrations produced during operation of the GDEs at $-0.31 \mathrm{~V}$ vs NHE. (1) Carbon fiber paper without any catalyst. (2) Carbon fiber paper 
coated with carbon black and 480\% PTFE. (3) Carbon fiber paper coated with 200 mesh graphite powder and $480 \%$ PTFE. (4) Carbon fiber paper coated with carbon black and 30\% PTFE.

$\mathrm{H}_{2} \mathrm{O}_{2}$ production by GDE 4 was subsequently tested in three 9-h experiments with $12 \mathrm{ml}$ catholyte volume at cathode potentials of $-0.16,-0.31$, and $-0.46 \mathrm{~V}$ vs NHE. The resulting concentrations and coulombic efficiencies were $374 \mathrm{mg} / \mathrm{L}$ (66.4\%), $1139 \mathrm{mg} / \mathrm{L}$ (78.6\%), and $3200 \mathrm{mg} / \mathrm{L}(87.2 \%)$, respectively. The $3200 \mathrm{mg} / \mathrm{L}$ concentration was within the target range of $0.2-0.5 \%$, so GDE 4 was used in the bioelectrochemical reactors.

\section{Bioelectrochemical $\mathrm{H}_{2} \mathrm{O}_{2}$ production}

Two GDEs of type 4 were made and used in the two bioelectrochemical reactors. The anodes in both reactors were initially single graphite rods. The reactors were inoculated with the effluent from a working microbial fuel cell. Initially both reactors were operated as microbial fuel cells with 1000 ohm resistors connected between the anode and cathode; this resistance was lowered to $100 \mathrm{ohm}$ on day 8 and to $10 \mathrm{ohm}$ on day 45 . After 40 days of operation, a carbon felt was attached to each anode to increase the total surface area available for bacterial growth and thereby increase the current delivered by the anode. On day 50, we started recirculating the anolyte through the anode chambers at a flow rate of $50 \mathrm{~mL} / \mathrm{min}$. On day 86 , real wastewater was fed to the anodes. The ability of the anodes to deliver current was evaluated using cyclic voltammetry (Figure 2). We can see that attaching a carbon felt to the anode increased current (compare day 37 and day 50 without recirculation) as this increased the surface area available for bacterial growth. During cyclic voltammetry, the anolyte was fed continuously to the anode chambers at a flow rate of $3.2 \mathrm{~mL} / \mathrm{min}$. Recirculating the anolyte at $50 \mathrm{~mL} / \mathrm{min}$ improved current output (compare the voltammograms from day 50). Using real wastewater as feed reduced the current output compared to synthetic wastewater (compare day 97 and day 50 with recirculation).
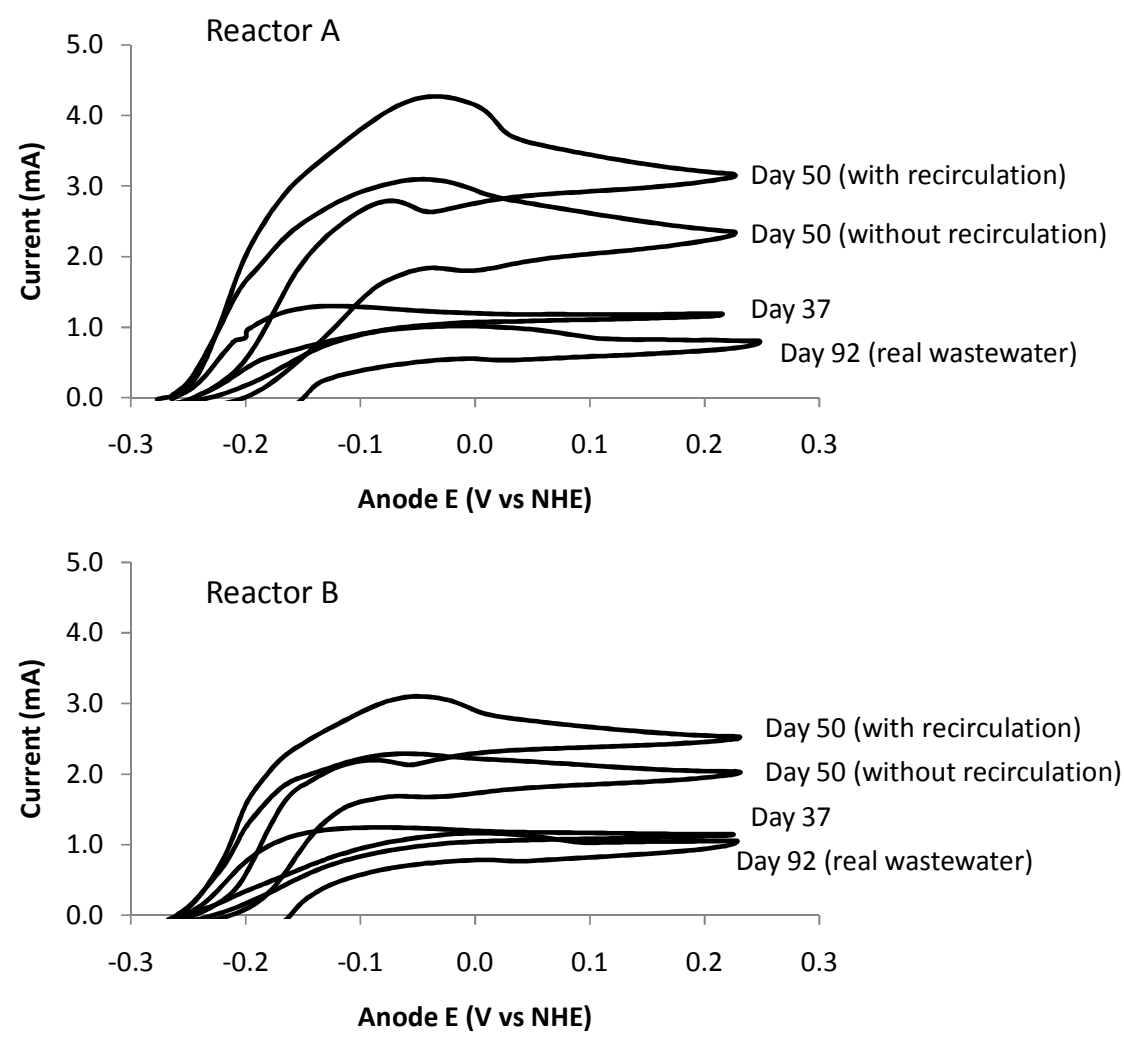

Figure 2. Cyclic voltammograms of the anode in Reactor A (upper) and Reactor B (lower). The current is plotted against the anode potential. 
$\mathrm{H}_{2} \mathrm{O}_{2}$ production was investigated by loading the cathode chambers with known volumes of $50 \mathrm{mM}$ $\mathrm{NaCl}$ solution and measuring the $\mathrm{H}_{2} \mathrm{O}_{2}$ concentration after a fixed time interval. The anode potential was controlled at $-0.11 \mathrm{~V}$ vs NHE and fed continuously with anolyte at a flow rate of $1.6 \mathrm{~mL} / \mathrm{min}$. The results are summarized in Table 1.

On day 40, 47, and 51, 2-h tests were carried out with both reactors. Higher concentrations were produced in Reactor B since it had smaller catholyte volume. Higher current led to higher $\mathrm{H}_{2} \mathrm{O}_{2}$ concentration as well as higher columbic efficiency (CE). On day 65, a 9-h test was carried out with Reactor B with the aim of reaching the $0.2-0.5 \%$ target concentration. This was successful as over $0.2 \%$ could be produced with an energy input of $1.01 \mathrm{kWh} / \mathrm{kgH}_{2} \mathrm{O}_{2}$ and a CE of $61 \%$. The required energy input was low compared to abiotic electrochemical reactors for $\mathrm{H}_{2} \mathrm{O}_{2}$ production, which may require 4.4-8.9 $\mathrm{kWh} / \mathrm{kgH}_{2} \mathrm{O}_{2}$ (Foller and Bombard, 1995).

On day 66, we operated the reactors as MFCs with a $10 \mathrm{ohm}$ resistor connected between anode and cathode. After $72.1 \mathrm{~h}$ operation, the $\mathrm{H}_{2} \mathrm{O}_{2}$ concentrations were approximately $0.06 \%$ and $0.08 \%$ in A and $\mathrm{B}$, respectively. This means that the reactors could produce $\mathrm{H}_{2} \mathrm{O}_{2}$ and electrical energy simultaneously.

Concentrations of nearly $0.5 \% \mathrm{H}_{2} \mathrm{O}_{2}$ could be produced after $46.9 \mathrm{~h}$ in Reactor A and $21 \mathrm{~h}$ in Reactor B. On day 104, another 21-h test was conducted with Reactor B using real wastewater. However, only $83.5 \mathrm{mg} / \mathrm{L}$ was produced, the $\mathrm{CE}$ was low, and the energy input was high.

There appears to be a correlation between final catholyte $\mathrm{pH}$ and CE. When the $\mathrm{pH}$ was over 11.28, the $\mathrm{CE}$ was over $50.3 \%$. When the $\mathrm{pH}$ was lower than 10.79 , the $\mathrm{CE}$ was lower than $28.1 \%$. A reason for low $\mathrm{CE}$ may be cathodic reduction of $\mathrm{H}_{2} \mathrm{O}_{2}$ to $\mathrm{H}_{2} \mathrm{O}$. The $\mathrm{pKa}$ of $\mathrm{H}_{2} \mathrm{O}_{2}$ is 11.62. If the $\mathrm{pH}$ is near or over this $\mathrm{pH}$ value, a large portion of the $\mathrm{H}_{2} \mathrm{O}_{2}$ will be present as the anion $\mathrm{HO}_{2}{ }^{-}$. Being negatively charged, $\mathrm{HO}_{2}{ }^{-}$will be repelled from the cathode, which is also negatively charged (Qiang et al., 2002). This would prevent further reduction to $\mathrm{H}_{2} \mathrm{O}$ and may explain the improved $\mathrm{CE}$ at higher $\mathrm{pH}$ values. Another reason for low $\mathrm{CE}$ could be self-decomposition of $\mathrm{H}_{2} \mathrm{O}_{2}$ according to Equation 2. This self-decomposition may have been catalyzed by metal ions migrating from the anode compartment through the cation exchange membrane to the cathode compartment. Diffusion of $\mathrm{H}_{2} \mathrm{O}_{2}$ to the anode compartment could also have resulted in lowering the CE.

$$
2 \mathrm{H}_{2} \mathrm{O}_{2} \rightarrow 2 \mathrm{H}_{2} \mathrm{O}+\mathrm{O}_{2}
$$

Low current was also correlated with low CE, which is especially evident in the tests with the reactors operated as MFCs and in the test with real wastewater, which both had the lowest currents and the lowest $\mathrm{CE}$. Low current corresponds to a low $\mathrm{H}_{2} \mathrm{O}_{2}$ production rate, which means that selfdecomposition processes may have been more dominating. Low current also means that the $\mathrm{pH}$ rise in the cathode will to a higher degree be counteracted by dissolution of $\mathrm{CO}_{2}$ from air. Thus, to improve the CE, a bioelectrochemical reactor should be designed with high anode surface area, which would maximize the generated current in relation to the cathode volume. 
Table 1. $\mathrm{H}_{2} \mathrm{O}_{2}$ production tests. Reactor A had a catholyte volume of $11 \mathrm{~mL}$ and Reactor $\mathrm{B}$ had 5 $\mathrm{mL}$. The anode was controlled at a potential of $-0.11 \mathrm{~V}$ vs NHE except on day 66 when the reactors were operated as MFCs.

\begin{tabular}{llllllll}
\hline Reactor A & Day 40 & Day 47 & Day 51 & & Day 66 & Day 76 \\
Run time $(\mathrm{h})$ & 2 & 2 & 2 & & 72.1 & 46.9 & \\
$\mathrm{H}_{2} \mathrm{O}_{2}$ conc. $(\mathrm{mg} / \mathrm{L})$ & 23.1 & 160.0 & 201.3 & & 601.9 & 4947.5 & \\
Final catholyte pH & 10.54 & 11.4 & 11.28 & & 10.54 & 12.35 & \\
$\mathrm{CE}^{\mathrm{a}}$ & $18.4 \%$ & $50.3 \%$ & $64.9 \%$ & & $13.5 \%$ & $51.3 \%$ & \\
Energy use $\left(\mathrm{kWh} / \mathrm{kgH}_{2} \mathrm{O}_{2}\right)$ & 1.17 & 2.29 & 1.63 & & $-238.2^{\mathrm{b}}$ & 2.27 & \\
Average I $(\mathrm{mA})$ & 1.08 & 2.75 & 2.69 & & 0.91 & 3.47 & \\
\hline Reactor B & Day 40 & Day 47 & Day 51 & Day 65 & Day 66 & Day 69 & Day 104 \\
Run time $(\mathrm{h})$ & 2 & 2 & 2 & 9 & 72.1 & 21 & 21 \\
$\mathrm{H}_{2} \mathrm{O}_{2}$ conc. $(\mathrm{mg} / \mathrm{L})$ & 76.9 & 357.8 & 643.0 & 2283.9 & 809.1 & 4588.8 & 83.5 \\
Final catholyte pH & 10.55 & 11.28 & 11.60 & 11.67 & 10.79 & 11.97 & 10.3 \\
$\mathrm{CE}^{\mathrm{a}}$ & $28.1 \%$ & $65.0 \%$ & $75.8 \%$ & $61.0 \%$ & $7.3 \%$ & $59.3 \%$ & $4.8 \%$ \\
Energy use $\left(\mathrm{kWh} / \mathrm{kgH}_{2} \mathrm{O}_{2}\right)$ & 0.30 & 0.75 & 1.32 & 1.01 & $-418.4^{\mathrm{b}}$ & 1.77 & 18.2 \\
Average I $(\mathrm{mA})$ & 1.08 & 2.17 & 3.34 & 3.28 & 0.95 & 2.90 & 0.65 \\
\hline
\end{tabular}

${ }^{\mathrm{a}}$ Colombic Efficiency (percentage of current charge equivalents used for $\mathrm{H}_{2} \mathrm{O}_{2}$ production).

${ }^{\mathrm{b}}$ Negative values means that power was produced instead of being consumed.

\section{Characterization of bioelectrochemical reactors}

The reactors were characterized by stepwise increasing the current and monitoring the resulting anode potential, cathode potential, and cell voltage. The cathode compartment of Reactor B was too small to accommodate a reference electrode; therefore, results are only shown for Reactor A. Figure 3 shows results from experiments carried out with synthetic wastewater on 86 and with real wastewater on day 99. The resistances associated with the anode reaction, cathode reaction, and the internal conductivity of the cell were estimated based on the slopes of the lines. The total resistance increased from $535 \pm 20 \Omega$ on day 86 to $1057 \pm 70 \Omega$ on day 99. As seen in Fig. 3, the cathode performance remained largely unchanged, so the deterioration in performance was caused by worse anode performance and higher internal ohmic resistance. The worse anode performance can be attributed to the bioanode culture being acclimated to acetate and the real wastewater not containing as much of this substance as the synthetic wastewater. The ohmic resistance increased from $342 \pm 29 \Omega$ to $539 \pm 103 \Omega$, which can be explained by the lower conductivity of the real wastewater, $127 \mathrm{mS} / \mathrm{m}$ compared to $777 \mathrm{mS} / \mathrm{m}$ for the synthetic wastewater.

With synthetic wastewater, the anode potential was lower than the cathode potential up to a current of about $2.3 \mathrm{~mA}$. However, because of the ohmic resistance of the cell, a voltage input was required for currents exceeding $0.6 \mathrm{~mA}$. Similarly for real wastewater, the anode potential was lower than the cathode potential up to $0.7 \mathrm{~mA}$, but a voltage input was required over $0.3 \mathrm{~mA}$. This indicates that if the ohmic resistance of the cell could be minimized, high concentrations of $\mathrm{H}_{2} \mathrm{O}_{2}$ could potentially be produced without energy input. 


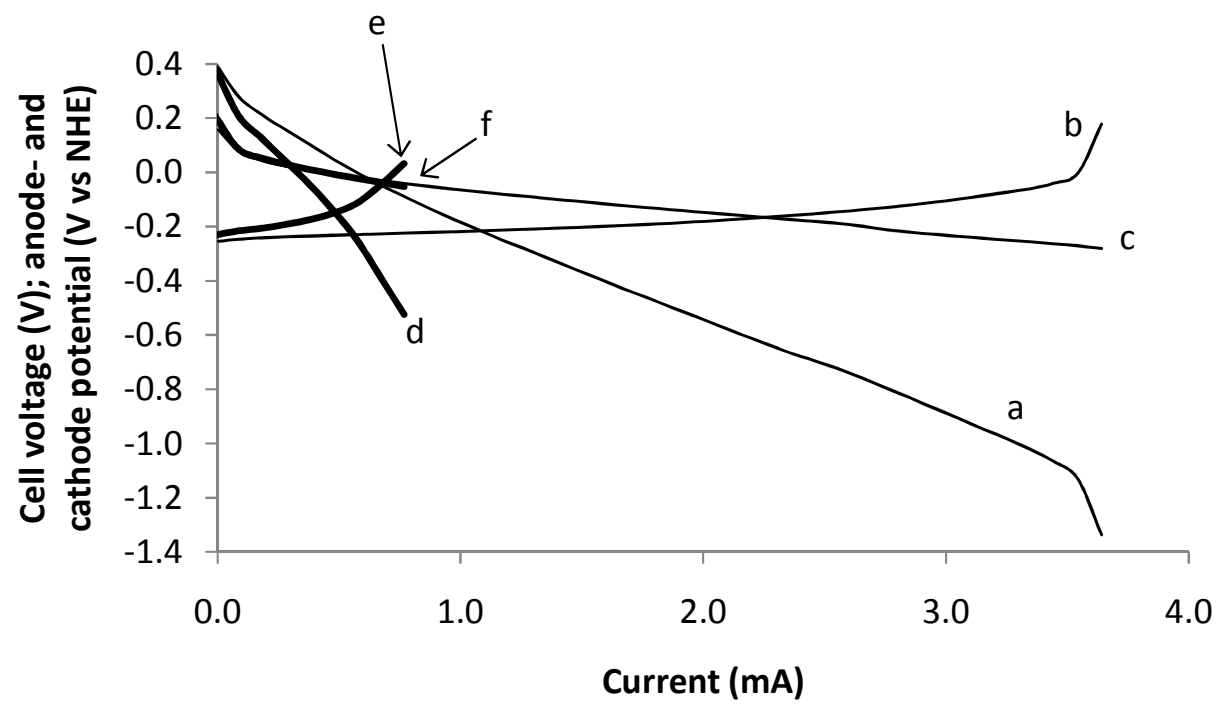

Figure 3. Cell voltage (a,d), anode potential (b,e), and cathode potential (c,f) on day 86 (a,b,c, thin lines, synthetic wastewater) and day 99 (d,e,f, thick lines, real wastewater).

The cation exchange membrane and GDEs were exchanged in the reactors on day 59. A white layer could be observed on the cathode side of the membrane (Figure 4). This was probably calcium carbonate deposits caused by calcium ions migrating from the anode compartment combining with carbonate ions present at high $\mathrm{pH}$ in the catholyte. This may have contributed to the high ohmic resistances of the cells. The GDEs seemed unaffected by these deposits.

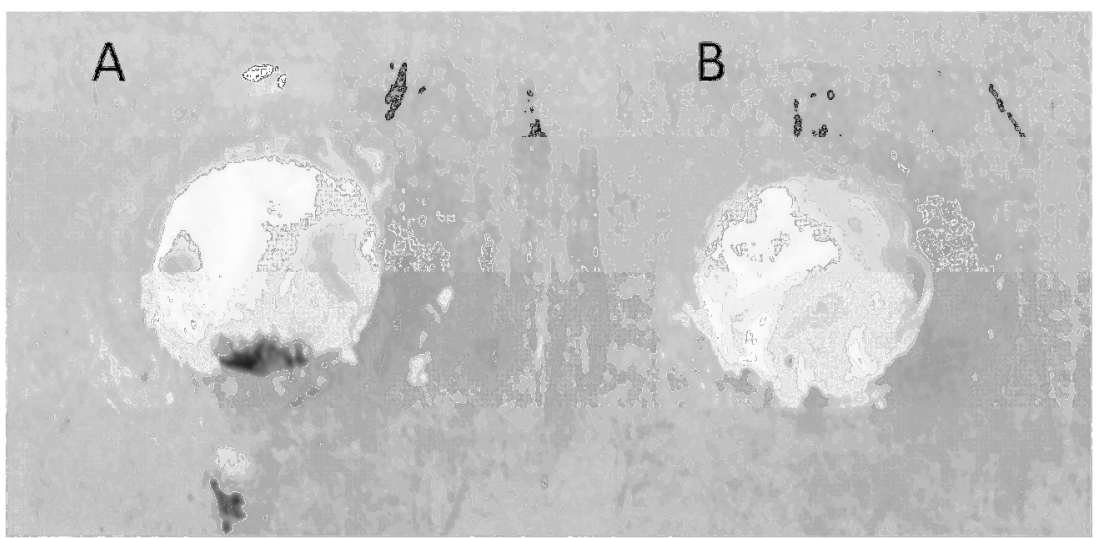

Figure 4. Nafion membranes harvested on day 59 of the experiment. White deposits were found on the cathode sides. The membranes are normally clear.

\section{CONCLUSIONS}

We made four GDEs and found that carbon nanoparticles bound with 30\% PTFE could catalyze oxygen reduction to $\mathrm{H}_{2} \mathrm{O}_{2}$ with $95.1 \%$ coulombic efficiency. A bioelectrochemical reactor constructed with this GDE and fed with synthetic wastewater to the anode could produce over $0.2 \%$ $\mathrm{H}_{2} \mathrm{O}_{2}$ in $9 \mathrm{~h}$ or $0.5 \%$ in $21 \mathrm{~h}$. These are concentrations that would likely be practically useful for membrane cleaning in MBR treatment plants.

Fed with real wastewater, the performance of the reactor deteriorated. The bioanode could only deliver a current less than a third in magnitude of the current delivered with synthetic wastewater. Furthermore, the internal resistance of the reactor increased because of the lower conductivity of the 
real wastewater. Another problem with the reactor was white deposits (probably calcium carbonate) on the cation exchange membrane.

The study showed that bioelectrochemical systems can be used to produce practically relevant concentrations of $\mathrm{H}_{2} \mathrm{O}_{2}$ with a low input of electrical energy. However, the bioanode must be designed to deliver current of sufficiently high magnitude. In our experiment, high $\mathrm{H}_{2} \mathrm{O}_{2}$ concentrations $(>0.2 \%)$ were produced with currents over $0.32 \mathrm{~mA} / \mathrm{mL}$ cathode volume. A volume of $0.006 \mathrm{~L}$ of $0.2 \% \mathrm{H}_{2} \mathrm{O}_{2}$ was produced per $\mathrm{L}$ synthetic wastewater fed to the anode chamber with an electric power consumption of $1.01 \mathrm{kWh} / \mathrm{kgH}_{2} \mathrm{O}_{2}$.

\section{ACKNOWLEDGEMENTS}

The project was supported by Japan Society for Promotion of Science (JSPS) KAKENHI (21360250). O.M. was supported by a post-doctoral fellowship from JSPS.

\section{REFERENCES}

Cheng, S., Xing, D., Call, D.F., Logan, B.E. (2009). Direct biological conversion of electrical current into methane by electromethanogenesis. Environmental Science \& Technology, 43, 3953-3958.

Clauwaert, P., Rabaey, K., Aelterman, P., de Schamphelaire, L., Pham, T.H., Boeckx, P., Boon, N., Verstraete, W. (2007). Biological denitrification in microbial fuel cells. Environmental Science \& Technology 41, 3354-3360.

Feng, C.H., Li, F-B., Mai, H-J., Li, X-Z. (2010). Bio-electro-fenton process driven by microbial fuel cell for wastewater treatment. Environmental Science \& Technology, 44, 1875-1880.

Foller, P.C., Bombard, R.T. (1995). Processes for the production of mixtures of caustic soda and hydrogen peroxide via the reduction of oxygen. Journal of Applied Electrochemistry, 25, 613627.

Fu, L., You, S-J., Yang, F-L., Gao, M-M., Fang, X-H., Zhang, G-Q. (2010). Synthesis of hydrogen peroxide in microbial fuel cell. Journal of Chemical Technology and Biotechnology, 85, 715719.

Grelot, A., Machinal, C., Drouet, K., Tazi-Pain, A., Schrotter, J.C., Grasmick, A., Grinwis, S. (2008). In search of alternative cleaning solutions for MBR plants. Water Science and Technology, 58(10), 2041.

Liu, H., Grot, S., Logan, B.E. (2005). Electrochemically assisted microbial production of hydrogen from acetate. Environmental Science \& Technology, 39, 4317-4320.

Logan, B.E., Hamelers, B., Rozendal, R., Schröder, U., Keller, J., Freguia, S., Aelterman, P., Verstraete, W., Rabaey, K. (2006). Microbial fuel cells: methodology and technology. Environmental Science \& Technology, 40(17), 5181-5192.

Modin, O., Fukushi, K., Rabaey, K., Rozendal, R.A., Yamamoto, K. (2010). Bioelectrochemical hydrogen peroxide production - an opportunity for sustainable mitigation of membrane bioreactor fouling. Proceedings of the Water Environment Federation, Biofilms 2010, 309-321 (DOI: http://dx.doi.org/10.2175/193864710798208566).

Modin, O., Fukushi, K., Rabaey, K., Rozendal, R.A., Yamamoto, K. (2011). Redistribution of wastewater alkalinity with a microbial fuel cell to support nitrification of reject water. Water Research, 45(8), 2691-2699.

Pletcher, D. (1999) Indirect oxidation using electrogenerated hydrogen peroxide. Acta Chemica Scandinavia, 53, 745-750. 
Rabaey, K., Butzer, S., Brown, S., Keller, J., Rozendal, R.A.. (2010). High current generation coupled to caustic production using a lamellar bioelectrochemical system. Environmental Science \& Technology, 44, 4315-4321.

Rozendal, R.A., Hamelers, H.V.M., Euverink, G.J.W., Metz, S.J., Buisman, C.J.N. (2006). Principles and perspective of hydrogen production through biocatalyzed electrolysis. International Journal of Hydrogen Energy, 31, 1632-1640.

Rozendal, R.A., Hamelers, H.V.M., Rabaey, K., Keller, J., Buisman, C.J.N. (2008). Towards practical implementation of bioelectrochemical wastewater treatment. Trends in Biotechnology, 26(8), 450-459.

Rozendal, R.A. ,Leone, E., Keller, J., Rabaey, K. (2009) Efficient hydrogen peroxide generation from organic matter in a bioelectrochemical system. Electrochemistry Communications, 11(9), 1752-1755.

Qiang, Z, Chang, J-H., Huang, C-P. (2002). Electrochemial generation of hydrogen peroxide from dissolved oxygen in acidic solutions. Water Research, 36, 85-94.

Sellers, R.M. (1980) Spectrophotometric determination of hydrogen peroxide using potassium titanium(IV) oxalate. Analyst, 105, 950-954.

Steinbusch, K.J.J., Hamelers, H.V.M., Schaap, J.D., Kampman, C., Buisman, C.J.N. (2010). Bioelectrochemical ethanol production through mediated acetate reduction by mixed cultures. Environmental Science \& Technology, 44, 513-517.

Trash, J.C., van Trump, J.I., Weber, K.A., Miller, E., Achenbach, L.A., Coates, J.D. (2007). Electrochemical stimulation of microbial perchlorate reduction. Environmental Science \& Technology, 41, 1740-1746.

Zhuang, L., Zhou, S., Li, Y., Liu, T., Huang, D. (2010). In-situ Fenton enhanced cathodic reaction for sustainable increased electricity generation in microbial fuel cells. Journal of Power Sources, 195, 1379-1382. 